\title{
Integration of human plasminogen or streptokinase into stable complexes with oxidoreductases and pyruvate kinase
}

\author{
Vitaly N. Nikandrov*, Oleg N. Murashko, Galina V. Vorobyova, Nelly S. Pyzhova, \\ Natalie V. Kvyatkovskaya and Oksana A. Bartalevich \\ Laboratory of Biochemistry, Byelorussian Research Institute of Epidemiology and Microbiology, K. Zetkin Str. 4, Minsk 220050, Belarus
}

Received 14 March 1997

Accepted 23 June 1997

Keywords: Plasminogen activation; Protein interactions; Secondary and tertiary structure

\section{SUMMARY}

The formation of stable equimolar complexes of streptokinase or plasminogen with muscle lactate dehydrogenase or pyruvate kinase, heart mitochondrial malate dehydrogenase and hepatic catalase at $\mathrm{pH}$ 7.4, 3.0 and 10.0 was first detected by differential spectroscopy methods. All complexes, except those of plasminogen with dehydrogenases, were resistant to $6 \mathrm{M}$ urea. Judging from circular dichroism spectra, tertiary and secondary structures were considerably changed in the complexes. These changes were significantly dependent upon the nature of interacting proteins; in some cases their structures were more ordered. NAD (but not NADH) hampered the formation of streptokinase complexes with dehydrogenases. The plasminogen-activating function of streptokinase and the ability of plasminogen to be activated by streptokinase in the complexes with oxidoreductases were essentially unchanged. Pyruvate kinase induced a moderate (by $35 \%$ ) increase in the streptokinase activating function. It is assumed that the formation of complexes of streptokinase or plasminogen with enzymes may serve as a link in metabolic regulation and/or intercellular interactions.

\section{INTRODUCTION}

The discovery of plasminogen $(\mathrm{Pg})$ specific receptors on several cell membranes, as well as the very important role of plasmin $(\mathrm{P})$ in the metastatic spreading of tumors [1,2], stipulates the necessity to understand the significance of $\mathrm{Pg}$ for the realization of series of physiological and pathological processes at the cellular level as well as the regulatory mechanisms of zymogen activation. Streptokinase (SK), a protein of $\beta$-hemolytic streptococci, is one of the most efficient $\mathrm{Pg}$ activators. It is assumed [3] that the $\mathrm{Pg}$ activation is catalyzed not by SK, which possesses hydrolase activity, but by an $\mathrm{SK}-\mathrm{P}(\mathrm{g})$ equimolar complex. The point of view that SK- antibodies and

\footnotetext{
* To whom correspondence should be addressed.
}

Pg are only protein ligands for stable complex formation with SK, held an important position among possible reasons for such a hypothesis of $\mathrm{Pg}$ activation by SK. Further, the formation of 'SK-lipoprotein $\mathrm{A}$ ' and 'SK-M-subunits of lactate dehydrogenase' complexes was described [4,5]. The formation of an SK-lipoprotein A complex leads to a decrease in $\mathrm{Pg}$ activation. Recently, we detected formation of equimolar SK as well as Pg complexes with native rabbit muscle lactate dehydrogenase (LDH, EC 1.1.1.27), bovine heart mitochondria malate dehydrogenase (MDH, EC 1.1.1.37), bovine liver catalase (EC 1.11.1.16) and rabbit muscle pyruvate kinase (PK, EC 2.7.1.40). Based on these data, we deemed it important to study the stability and conformational and functional properties of such com- 
plexes. In the present study, we investigate the effects of solution properties on formation of SK or Pg complexes with enzymes, and the characteristics of their secondary and tertiary structures and Pg activation.

\section{MATERIALS AND METHODS}

Purified samples of rabbit muscle LDH and PK, bovine heart mitochondria MDH, and bovine liver catalase (Reanal, Budapest, Hungary) were used in our experiments. The human Pg samples were prepared from a $\beta$-globulin enriched fraction by affinity chromatography on lysine-Sepharose; SK was isolated from the 'Celyase' drug (Belarus) by column chromatography with Blue Agarose. The methods of purification of the proteins, their indication of homogeneity, activity and their characteristics were described in our previous papers [8,9]. We also used Sepharose 4B CNBr (Pharmacia, Uppsala, Sweden), lysine, NADH, NAD and reagents for electrophoresis on polyacrylamide gel (Reanal). The other reagents were of the highest commercially available grade.

The formation of complexes was monitored by differential spectroscopy using a Specord M40 spectrophotometer at $25{ }^{\circ} \mathrm{C}$ and $\mathrm{pH} 7.4(0.06 \mathrm{M} \mathrm{Na}-$ phosphate buffer), $\mathrm{pH} 3.0$ (0.2 $\mathrm{M}$ acetate buffer), or pH 10.0 (0.2 M NaOH-borate buffer) as described previously [8]; the concentration of proteins was $10^{-6} \mathrm{M}$ or $2.5 \times 10^{-5} \mathrm{M}$. Circular dichroism spectra were recorded on a Jasco-20 spectropolarimeter. The spectral simulation and spectral parameters were described in previous papers $[8,9]$. Protein concentration in solutions was determined spectrophotometrically according to the absorbance of aqueous solutions at $280 \mathrm{~nm}$, taking $\mathrm{A}_{1}^{1 \%} \mathrm{~cm}: 8.8(\mathrm{SK}), 17.0(\mathrm{Pg})$, $12.0(\mathrm{LDH}), 2.5(\mathrm{MDH}), 15.8$ (276 nm, catalase) and 5.4 (PK) $[8,10-13]$. The Pg-activating function of the complexes was analysed by the $\mathrm{Pg}$-containing fibrin plate lysis method, and the ability of SK to activate the Pg-enzyme complexes was studied on fibrin plates, which were preliminarily UV irradiated to inactivate fibrin-bound $\mathrm{Pg}$. These methods were described in a previous paper [14]. All studies were repeated at least four times.

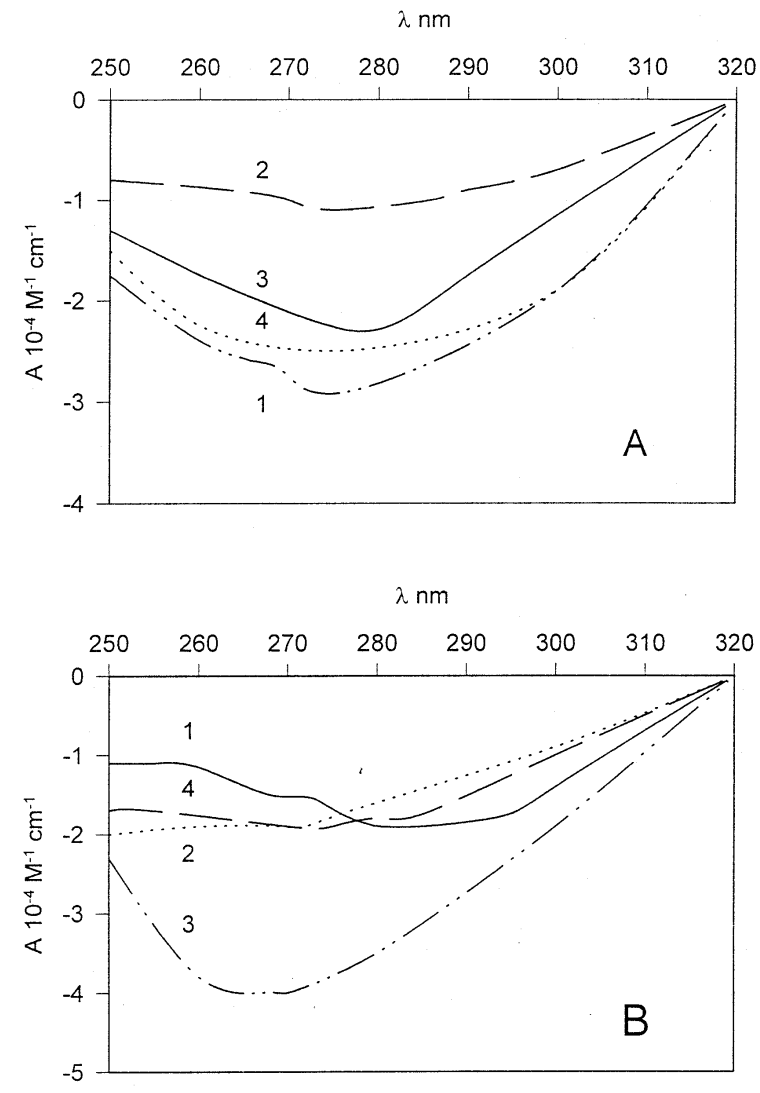

Fig. 1. Difference spectra of equimolar mixtures of streptokinase (A) or plasminogen (B) with muscle lactate dehydrogenase (1), heart mitochondrial malate dehydrogenase (2), hepatic catalase (3), and muscle pyruvate kinase (4). In all cases the solvent was $0.06 \mathrm{M}$ phosphate buffer, $\mathrm{pH} 7.4$, the final concentration of the proteins was $10^{-6} \mathrm{M}$, the temperature was $25^{\circ} \mathrm{C}$.

\section{RESULTS AND DISCUSSION}

Mixing SK solutions with the enzymes resulted in the formation of differential spectra, the character of which was dependent on the interacting proteins (Fig. 1; Table 1). This indicates the changes in protein chromophore surroundings as the result of SK-enzyme complex formation.The form and amplitude of differential spectra did not change significantly within $30 \mathrm{~min}$. Judging from the spectra, a $\mathrm{pH}$ shift or addition of $6 \mathrm{M}$ urea did not influence complex formation. Consequently, SK-enzyme complexes appear more stable than SK-Pg ones. As will be demonstrated below, this is true for $\mathrm{Pg}$ catalase (or PK) complexes too. These facts and the 